JURNAL ILMIAH ELEKTRONIKA DAN KOMPUTER, Vol.11, No.2, Desember 2018, pp. 1 - xxx

p-ISSN : 1907-0012 (print)

e-ISSN : 2714-5417 (online)

http://journal.stekom.ac.id/index.php/elkom

- page 1

\title{
IMPLEMENTASI SISTEM INFORMASI GEOGRAFIS BIDANG PENDIDIKAN (Studi Kasus Kecamatan Tugu Semarang)
}

\author{
Hendri Rasminto \\ Program Studi Magister Sistem Informasi \\ Universitas Kristen Satya Wacana \\ Salatiga \\ hendri@stekom.ac.id
}

\section{ARTICLE INFO}

Article history:

Received 30 November 2018

Received in revised form 2 Desember 2018

Accepted 10 Desember 2018

Available online 12 Desember 2018

\section{ABSTRACT}

At present the information of schools in various fields of education in the Tugu sub-district is still incomplete that only covers the TK / RA and SD / MI levels so that the wider community has not been able to obtain information on the level of education at SMP / MTs, SMA / SMK / MA and Higher Education, and to get this information the public must come directly to the Semarang City Education Office to find the data needed. The public cannot know quickly if there is a change in data or if there is a construction of a new school because the information is only written on the sub-district bulletin board.

Tugu sub-district is a sub-district in the city of Semarang, Central Java province. Tugu sub-district region is bordered by the Java sea in the north, in the east by West Semarang Sub- district, in the south by Ngalian sub-district, and in the west by Kendal district. Tugu sub-district has an area of $\pm 3.444,22$ Ha hectares, consisting of 7 kelurahan, namely Jrakah, Tugurejo, Karanganyar, Randugarut, Mangkang Wetan, Mangunharjo and Mangkang Kulon [7]

Various suggestions appear to help equip human work to be more efficient and productive, we need a system that can help the work needed by a web-based Geographic Information System. Geographic Information System is a computer-based system for processing data or information that has a geographical dimension [1]. The program used in research uses the PHP programming language, JAVA SCRIPT because this program can be run on a server and is quite reliable using a MySQL database. [3]

Keywords: Information, System, Geographic, GIS, Website 


\section{Pendahuluan}

Pada saat ini teknologi informasi mempunyai perkembangan pesat, penemuan model ataupun jenis teknologi akan semakin pesat dari tahun ke tahun [6] Perkembangan Teknologi Informasi yang cepat menyebabkan informasi memegang peranan yang penting dan tidak dapat dipisahkan dari kehidupan manusia. Sistem merupakan perangkat yang sangat mutlak dan harus ada dalam hal mengorganisasikan seseorang, perusahaan dan instansi pemerintahan.

Sejalan dengan kenyataan yang terjadi sekarang ini, perkembangan teknologi cukup pesat, seperti teknologi internet. Internet merupakan media penyampaian informasi yang cepat. Dengan demikian baik seseorang, perusahaan dan instansi pemerintah dapat memanfaatkan internet untuk memberikan informasi kepada masyarakat luas.

Kecamatan Tugu merupakan salah satu Kecamatan yang berada di kota Semarang provinsi Jawa Tengah. Wilayah kecamatan Tugu sebelah utara berbatasan dengan laut Jawa, sebelah timur berbatasan dengan Kecamatan Semarang Barat, sebelah selatan berbatasan dengan Kecamatan Ngalian, serta sebelah barat berbatasan dengan Kabupaten Kendal. Kecamatan Tugu memiliki luas wilayah \pm 3.444,22 Ha, yang terdiri dari 7 Kelurahan yaitu Kelurahan Jrakah, Tugurejo, Karanganyar, Randu garut, Mangkang Wetan, Mangunharjo dan Mangkang Kulon. [7]

Pada saat ini informasi sekolah-sekolah dengan berbagai bidang pendidikan yang ada di Kecamatan Tugu masih belum lengkap yaitu hanya mencakup tingkat TK/RA dan SD/MI sehingga masyarakat luas belum bisa mendapatkan informasi jenjang pendidikan tingkat SMP/MTs, SMA/SMK/MA dan Perguruan Tinggi, dan untuk mendapat informasi tersebut masyarakat harus datang langsung ke Dinas Pendidikan kota Semarang untuk mencari data yang dibutuhkan. Masyarakat tidak bisa mengetahui dengan cepat apabila ada perubahan data ataupun jika ada pembangunan sekolah baru karena informasinya hanya di tulis di papan pengumuman Kecamatan saja.

Tabel 1.1 Perbedaan Data Sekolah Di UPTD Pendidikan Kecamatan Tugu dan Dinas Pendidikan Kota Semarang

\begin{tabular}{|l|l|c|c|}
\hline NO & \multicolumn{1}{|c|}{ Tingkat Sekolah } & $\begin{array}{c}\text { Kecamatan } \\
\text { (Unit) }\end{array}$ & $\begin{array}{c}\text { Dinas } \\
\text { (Unit) }\end{array}$ \\
\hline 1 & TK & 9 & 9 \\
\hline 2 & RA & 7 & 7 \\
\hline 3 & SD & 14 & 14 \\
\hline 4 & MI & 8 & 8 \\
\hline 5 & SMP & Tidak dicatat & 5 \\
\hline 6 & MTS & Tidak dicatat & 3 \\
\hline 7 & SMA & Tidak dicatat & 0 \\
\hline 8 & SMK & Tidak dicatat & 1 \\
\hline 9 & MA & Tidak dicatat & 2 \\
\hline 10 & Perguruan Tinggi & Tidak dicatat & 1 \\
\hline
\end{tabular}

Keterangan :

Tidak dicatat : Tidak ada data yang tercatat, karena UPTD Pendidikan Kecamatan Tugu hanya mengolah data TK/RA, SD/MI.

0 (nol) : : Tidak ada SMA.

Sumber Data : UPTD Pendidikan Kecamatan Tugu dan Dinas Pendidikan Kota Semarang tahun 2019

Pada tahun ajaran 2018-2019 UPTD Pendidikan Kecamatan Tugu sudah mendata peserta didik yang masuk jenjang pendidikan tingkat TK mencapai 285 siswa baru, RA 196 siswa baru, SD 417 siswa baru, MI 158 siswa baru, yang mungkin akan terus bertambah tiap tahun ajaran baru, selain itu di UPTD Pendidikan Kecamatan Tugu tidak mencatat informasi jenjang pendidikan tingkat SMP/MTs, SMA/SMK/MA dan Perguruan Tinggi, karena datanya langsung diolah oleh Dinas Pendidikan Kota Semarang.

Untuk membantu agar informasi tentang sekolah-sekolah dengan berbagai bidang pendidikan di Kecamatan Tugu bisa diketahui dengan mudah oleh pemerintah ataupun masyarakat, maka penulis mengadakan penelitian dengan judul "Sistem Informasi Geografis Bidang Pendidikan Pada Kecamatan

JURNAL ILMIAH ELEKTRONIKA DAN KOMPUTER, Vol.11, No.2, Desember 2018, 
Tugu Semarang” dengan harapan bisa memberikan informasi yang lengkap tentang keberadaan sekolahsekolah dengan berbagai bidang pendidikan yang ada di Kecamatan Tugu.

\section{Perumusan Masalah}

Dari latar belakang diatas terdapat beberapa masalah yang timbul dalam menginformasikan sekolah yang ada di Kecamatan Tugu yaitu :

1. Informasi sekolah-sekolah dengan berbagai bidang pendidikan yang ada di Kecamatan Tugu masih belum lengkap yaitu hanya mencakup tingkat TK/RA dan SD/MI sehingga masyarakat belum bisa mendapatkan informasi tingkat SMP/MTs, SMA/SMK/MA dan Perguruan Tinggi.

2. Masyarakat kesulitan mendapatkan data sekolah-sekolah dengan berbagai bidang pendidikan di Kecamatan Tugu, karena harus datang langsung ke Kecamatan Tugu ataupun Dinas Pendidikan Kota Semarang.

3. Masyarakat tidak bisa mengetahui dengan cepat apabila ada perubahan data ataupun jika ada pembangunan sekolah baru karena informasinya hanya di tulis di papan pengumuman Kecamatan saja.

\section{METODE PENGEMBANGAN}

1. Subjek Penelitian

Subjek penelitian adalah subjek yang dituju untuk diteliti . Subjek penelitian jugadapat merupakan dimana tempat objek penelitian itu berada [2]. subjek penelitian ini pada Dinas Pendidikan Kota Semarang yang beralamatkan di jalan Dr.Wahidin 118 Semarang dan sekolahsekolah dengan berbagai bidang pendidikan terkait.

2. Jenis-jenis Data

a. Data Kualitatif

Data Kualitatif adalah data yang dilihat dari satu sisi perlu atau tidaknya data tersebut digunakan dalam sebuah penelitian sehingga dapat menghasilkan informasi yang tepat dan berguna.

b. Data Kuantitatif

Data kuantitatif adalah data yang diperlukan dalam sebuah penelitian yang dilihat dalam sisi jumlah sehingga dapat memberikan informasi yang tepat dan berguna. [2]

3. Sumber Data

a.. Data Primer

Data primer adalah data yang diperoleh langsung dari pengamatan dari objek penelitian [2] yaitu di Kecamatan Tugu.

b. Data Sekunder

Data sekunder adalah data yang diperoleh dari buku-buku atau literatur-literatur yang menunjang penyusunan penelitian. [2]

4. Metode Pengumpulan Data

Metode ini bertujuan untuk mengumpulkan informasi, yaitu apa yang diperlukan untuk menentukan dan mengenali masalah serta tujuan sistem.

Metode ini meliputi :

a. Observasi

Merupakan suatu cara pengumpulan data dengan cara mengamati ketersediaan informasi langsung pada objek penelitian [4] yaitu di Dinas Pendidikan Kota Semarang dan sekolah-sekolah dengan berbagai bidang pendidikan terkait.

b. Wawancara

Merupakan metode pengumpulan data dengan mengadakan wawancara secara langsung [4] dengan staff Dinas Pendidikan untuk mendapatkan data yang diperlukan. c.Studi Pustaka

Merupakan metode pengumpulan data yang diperoleh dari internet, buku-buku yang masih relevan dengan judul yang diambil. [4]

5. Metode Pengembangan Sistem

Penulis menentukan metode SLC untuk tugas mengembangkan dan menggunakan sistem berbasis komputer. Langkah-langkah SLC secara evolusioner ada 5 tahap, 4 tahap pertama adalah perencanaan, analisis, rancangan dan penerapannya. Tahap-tahap tersebut cenderung kearah pengembangan sistem. SLC tersebut juga dapat diartikan serangkaian tugas secara bertahap dan

IMPLEMENTASI SISTEM INFORMASI GEOGRAFIS BIDANG PENDIDIKAN (Studi Kasus

Kecamatan Tugu Semarang) 
urutan serta teratur yang dilakukan secara top down, sehingga SLC juga disebut pendekatan air terjun. 4 tahap yang pertama dalam SLC dapat dipacu lebih cepat dan lebih responsif dengan peralatan pengembangan berbasis komputer. Tahap ke 5 dalam SLC adalah tahap penggunaan sistem tersebut yang berlangsung sampai diperlukan merancang sistem itu kembali karena perlu diperbarui.

Berikut ini adalah gambar lingkaran SLC dan penjelasanya:

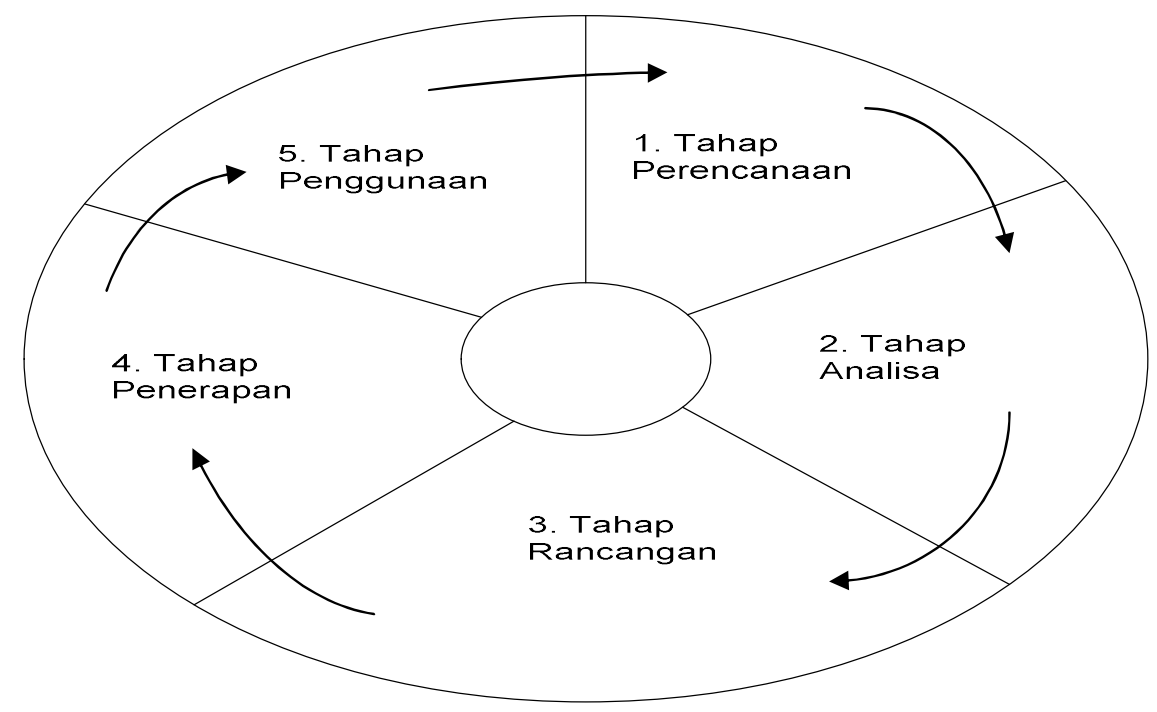

Gambar 1.1. Lingkaran SLC

(Sumber : Raymound McLeod, 2018)

Penjelasannya :

1. Tahap Perencanaan

Tahap ini meliputi 8 tahapan lagi yang intinya merupakan tahap untuk merencanakan penelitian.

Yaitu:

a.Menyadari masalah.

b.Mendefinisikan masalah.

c.Menentukan tujuan sistem.

d.Mengidentifikasi kendala-kendala sistem.

e.Membuat study kelayakan.

f. Mempersiapkan usulan penelitian sistem.

g.Menyetujui atau menolak penelitian proyek.

h.Menetapkan mekanisme pengendalian.

2. Tahap Analisis

Tahap ini dilakukan pada saat tahap perencanaan telah selesai dan mekanisme pengendalian umum sudah berjalan.

3. Tahap Rancangan Sistem

Tahap ini dapat dibagi 2 bagian yaitu desain sistem secara umum dan secara rinci.

4. Tahap penerapan Sistem

Merupakan tahapan memperoleh dan mengintegrasikan sumber daya fisik dan konseptual yang menghasilkan sistem yang bekerja.

5. Tahap Penggunaan Sistem

Tahap ini biasa disebut tahap perawatan, jika sampai dengan tahap perawatan ini sistem yang digunakan tidak dapat diperbaiki atau di tingkatkan penggunaanya maka tahap ini menjadi titik balik dari semua tahapan yang dilalui untuk kembali pada tahapan pertama dalam siklus hidup sistem yaitu tahap perencanaan. [5]

JURNAL ILMIAH ELEKTRONIKA DAN KOMPUTER, Vol.11, No.2, Desember 2018, 


\section{HASIL DAN PEMBAHASAN}

A. Hasil Pengembanganan

Sistem yang dikembangkan saat ini tidak lepas dari kebutuhan yang ada di UPTD Kecamatan Tugu Semarang, adapun analisa yang mendorong adanya pengembangan kepada sistem yang lebih baik terutama pada bagian penyampaian informasi data sekolah dengan tujuan memudahkan masyarakat untuk melakukan pencarian data dan informasi yang berhubungan dengan TK/RA, SD/MI, SMP/MTs, SMA/SMK/MA dan Perguruan Tinggi yang berada di kecamatan Tugu melalui Website, mengetahui perubahan informasi tentang sekolah-sekolah dengan berbagai bidang pendidikan yang ada di Kecamatan Tugu secara uptodate, merancang pemrograman aplikasi informasi geografis bidang pendidikan di Kecamatan Tugu supaya masyarakat bisa mendapatkan informasi yang lengkap tentang keberadaan sekolah-sekolah dengan berbagai bidang pendidikan yang ada di Kecamatan Tugu dengan mudah.

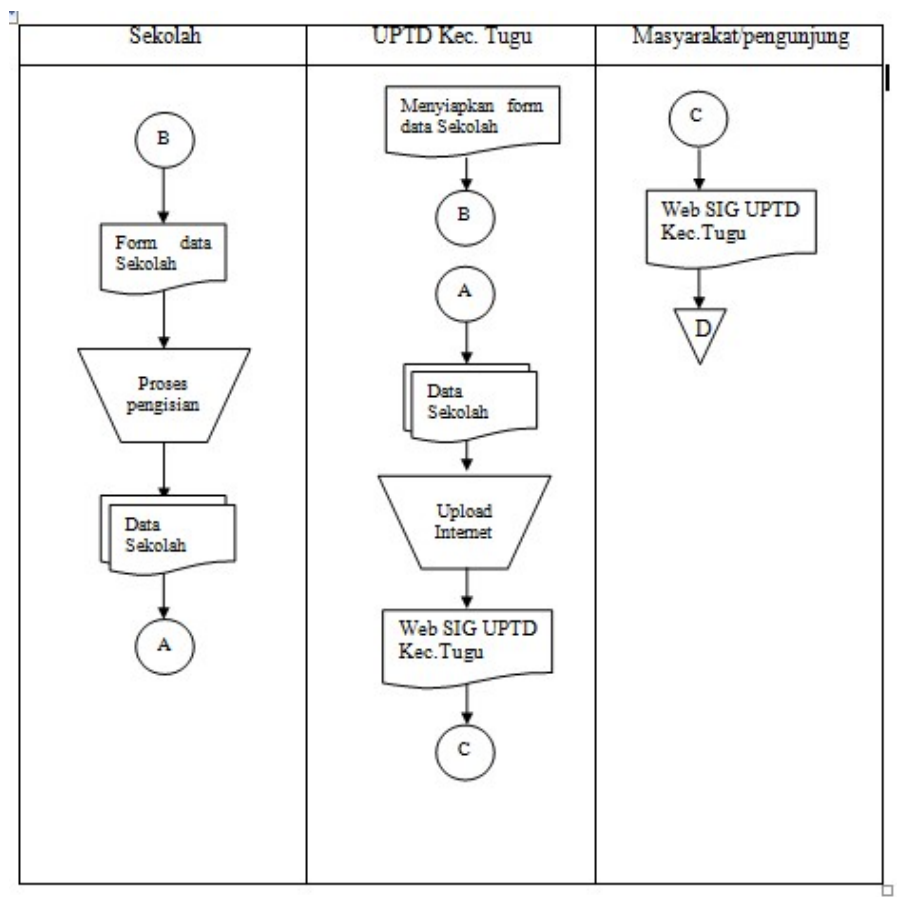

Tabel 3.1 Flowchart Sistem baru

Narasi Flow Of Document rancangan baru :

1. UPTD menyerahkan form pertanyaan kepada sekolah-sekolah untuk di isi.

2. Kemudian tiap sekolah menyerahkan data kepada UPTD Kecamatan Tugu Semarang.

3. Setelah itu data dicatat dan diolah menjadi profil sekolah.

4. Setelah berbentuk profil sekolah yang valid, kemudian di upload ke situs SIG UPTD Kecamatan Tugu.

5. Setelah di upload ke situs SIG UPTD Kecamatan Tugu, masyarakat/pengunjung dapat mendapatkan informasi yang dibutuhkan

\section{KESIMPULAN}

Dengan selesainya perancangan dan uji coba "Sistem Informasi Geografis Bidang Pendidikan pada Kecamatan Tugu Semarang” maka dapat diperoleh manfaat sebagai berikut :

1. Memudahkan masyarakat untuk melakukan pencarian data dan informasi sekolah-sekolah dan Perguruan Tinggi yang berada di kecamatan Tugu melalui Website.

2. Masyarakat dapat mengetahui adanya perubahan informasi tentang sekolah-sekolah dengan berbagai bidang pendidikan dan berita-berita tentang sekolah yang ada di Kecamatan Tugu secara uptodate.

3. Memudahkan sekolah-sekolah yang ada di Kecamatan Tugu untuk memberikan data yang cepat ke UPTD Kecamatan Tugu dan bisa juga sebagai media promosi untuk masyarakat luas melalui Website.

IMPLEMENTASI SISTEM INFORMASI GEOGRAFIS BIDANG PENDIDIKAN (Studi Kasus

Kecamatan Tugu Semarang) 
DAFTAR PUSTAKA

[1] Adil, Ahamad. 2019, Sistem Informasi Geografis, Andi, Yogyakarta

[2] Ansori, Muslich. 2018, Metodologi Penelitian Kuantitatif, Airlangga University press, Surabaya

[3] Juju, Dominikus, Syukrie Muhammad. 2009. Jurus Jitu Pembuatan Web Freelance, P.T Media Elex Komputindo, Jakarta.

[4] Martono, Nanang, 2019 , Metodologi penelitian Kuantitatif, cetakan -4 ISBN 978-979-769-749-5, PT. Raja Grasindo Persada, Jakarta

[5] McLeod, Raymond. 20018. Manajemen Information System, 8th Edition, Prentice Hall International.

[6] Nuryanto, Hery. 2019. Sejarah Perkembangan Teknologi Informasi Dan Komunikasi, PT.Balai Pustaka

[7] Tugu, 2020. Peta Aministrasi Kecamatan Tugu Kota Semarang, http://kectugu.semarangkota.go.id/profile-kecamatan

JURNAL ILMIAH ELEKTRONIKA DAN KOMPUTER, Vol.11, No.2, Desember 2018, 